\title{
Knowledge Management infrastructure for Governmental Ubiquitous Services
}

\author{
Mohammad Hassanzadeh \\ Tarbiat Modares University \\ hasanzadeh@modares.ac.ir
}

\author{
Babak Akhgar \\ Sheffield Hallam University \\ b.akhgar@shu.ac.uk
}

\author{
Simeon Yates \\ Sheffield Hallam University \\ s.yates@shu.ac.uk
}

\begin{abstract}
Knowledge has become as a key strategic component of economic development. The World Development Report published by the World Bank precisely emphasized: "For countries in the vanguard of the world economy, the balance between knowledge and resources has shifted so far toward the former that knowledge has become perhaps the most important factor determining the standard of living - more than land, than tools, than labor". The moves towards a knowledge based economy by the government of the Islamic Republic of Iran (IRI), which includes a move towards knowledge management (KM) in government, is an example of a policy response to this new global situation. This article reports on empirical research that has examined two aspects of the implementation of this policy. First, an investigation of KM infrastructures in IRI government departments, and second, levels of user centred architectures for effective deployment of KM within IRI governmental organizations. Twenty government ministries were selected for the study. These ministries provided data on the six KM infrastructural components identified from theory. Data covering sector and organizational aspects of $\mathrm{KM}$ implementation were collected using questionnaires. The first part of the questionnaire was completed by plan, budget and ICT offices and covered three components: 1] strategy and policies; 2] information and communication technology; and 3] KM finance. The second part of the questionnaire which was completed by all offices, contained questions about three further components: 1] organizational arrangements; 2] staff development and mobility and 3] organizational culture. In total 314 questionnaires were completed and specific comparisons and correlations were statistically analysed using ANOVA, $t$ and Pearson's Correlation Co-efficients. Findings show different focus points in different ministries and sectors and significant relations between supportive organizational culture around KM and the level of infrastructures organizations are provided with. Problems were identified with regard to the management of organizational knowledge. Detailed discussion of the quantitative findings and analysis together along with the proposed user centric KM deployment architecture are reported in this paper.
\end{abstract}

\section{Keywords: Knowledge management, knowledge sharing, infrastructures, KM deployment.}

\section{INTRODUCTION}

Over the past two decades knowledge has increasingly become a key component of struggles toward sustainable development. The Organization for Economic Co-Operations and Development (OECD) emphasized the importance of the knowledge economy and the role of knowledge for economic development in the third millennium (OECD, 1996). The World Development Report published by the World Bank argued that:

"For countries in the vanguard of the world economy, the balance between knowledge and resources has shifted so far toward the former that knowledge has become perhaps the most important factor determining the standard of living - more than Land, than tools, than labor" (World Bank, 1998).
World Bank again emphasized the importance of the knowledge assets of nations and considered how the implementation of policy and methods around knowledge assets were key to developing countries participating effectively in the knowledge revolution (World Bank, 2002).

The 4th development plan (2005-2009) of the Government of the Islamic Republic of Iran (IRI) identified knowledge based development as an important strategy. In the 4th development plan two chapters are specifically allocated to this concept: chapter1 that explores developing a national knowledge based economy and chapter 4 that explores knowledge based development (IRI 4th Plan, 2005-2009). The emphasis on knowledgebased growth remained in the 5th development. These statements are clear indications that the IRI also views knowledge as an important asset. 
Knowledge is therefore an asset which government should try to manage effectively in order to increase national competitiveness. Implicit $\mathrm{n}$ such policies are assumptions about the importance of Knowledge Management as a key vehicle to achieve such objectives.

According to OECD Knowledge Management (KM) is a broad collection of organizational practices related to the creation, capture, and dissemination of organizational knowledge and the improvement of knowledge sharing culture within organizations (OECD, 2003). We label the flow of knowledge in an organisation's KM systems and knowledge sharing culture as the organizational knowledge life cycle. At the governmental level we extend the OECD definition and define KM as:

\begin{abstract}
"A process of creating value added learning processes (i.e. knowledge) so that the knowledge becomes the strategic resource of a country with measurable and quantifiable value."
\end{abstract}

By quantifiable value we are referring to the growth of capital following utilisation of knowledge within national boundaries and extending national value chains (such as trade relations and international knowledge exchange and transfer).

Implementing knowledge management in organizations requires infrastructures to support the knowledge life cycle. Figure 1 represents what we consider the baseline infrastructure for $\mathrm{KM}$, this is based on the research by Akhgar et al.(2011).

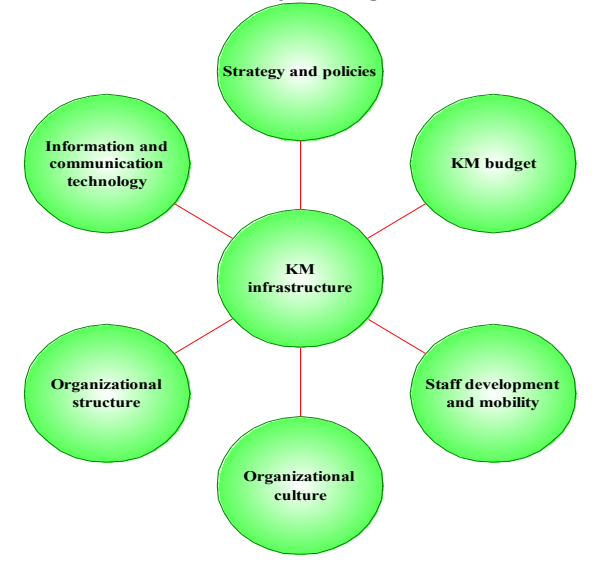

Figure 1 Basic infrastructure to support knowledge life cycle

The first part of this study sought to address a basic question:

- How did ministries in IRI prepare and provide the infrastructure for knowledge management implied by policy objectives?

We made our assessment by considering six baseline components that we considered the main critical success factors: (i) Strategy and policies. Does the organization give priority to $\mathrm{KM}$ in their strategy and policies?

(ii) Information and communication technology. How much does the organization apply ICT tools to the management and sharing of knowledge?

(iii) KM budget. Is there any allocated budget for KM initiatives?

(iv) Organizational structure. Are there suitable organizational arrangements to establish KM programmes?

(v) Staff development and mobility (HRM issues). Is there any plan in the organization to promote staff members acquisition of a greater knowledge base?

(vi) Organizational culture. Are organizations prepared to support the sharing of organizational knowledge?

The second part of this study is focused around a proposed architecture to enable governmental organizations to effectively deploy KM. The proposed architecture focuses on the human centric element of $\mathrm{KM}$ and technological issues related to the realization of the architecture.

There is a wide range of technologies available to support KM although there is no definitive market leader. Akhgar and Siddiqi (2001) suggest a taxonomical categorisation of KM applications in terms of their functionality. They have suggested a framework for categorisation of $\mathrm{KM}$ application based on the KM life cycle. From the philosophical perspective current KM applications and tools are predominately 'ontology' driven either by design or by their underlying approach. Therefore the dominant ways of gathering, organising, representing and distributing knowledge is through defining explicit relationships among different concepts. This is captured in the form of an 'ontology' that may be used to build the concept model, which is the collection of concepts and conceptual relationships within systems. An example of an open source tool for such work is OWL. Such tools enable representations and facilitate automatic reasoning and inferences. In ontology driven $\mathrm{KM}$ solutions for a given problem there can be a set of pre-defined solutions with fixed and pre-defined value propositions. Within Ontology driven solutions the essential mode of knowledge can be viewed as analogous to one where we consider knowledge as the dependent variable $(K)$ of a basic production function $(f)$ such that:

$$
K=f\left(x_{1}, x_{2}, x_{3} \ldots x_{n-1} x_{n}\right)
$$

Where the independent variables $\left(x_{1}, x_{2}\right.$ etc) are defined organisational factors such as human based organizational information, historical data, information technology and so forth. The 
organisation's 'knowledge' is therefore the sum at any point of the combined effects of these factors. As with production functions in microeconomics, in assuming that that the maximum output technologically possible from a given set of inputs is achieved the approach abstracts from the engineering and managerial realities inherently associated with a particular knowledge production and management process.

The 'knowledge' has been considered a static element with a linear relationship with its constituent parts namely: data; information; representation of data and information; concepts; vocabularies; semantics; explicit specifications and descriptions. Considerations about the processes of change over time in organizational and human knowledge needs are not included. Such an approach is therefore a starting point for mapping and measuring the current knowledge life cycle as a route to understanding current practice - but it does not provide a model for process change over time.

In this paper we have mapped and measured current context through identifying a scoring six key factors, but we also look to alternate approaches to the problem to support the development of an approach where the organisational context is more dynamic and in a process itself of dynamic change, in part driven by the need to best utilise its knowledge base.

Given the dynamic nature of the governmental environment and constant changes to business and societal needs, purely ontology driven solutions may have both limited impact and return on investment (ROI). This is due to the fact that they are by nature providing a "solution" to "a problem" based on identified highly structured and static relationships. Where user practices, knowledge and representations are very well established standards based on a well research and rich ontology can be very powerful. In more dynamic contexts of organisational and societal change a more flexible approach is needed.

Akhgar (2009) proposed an 'epistemologically driven' approach to KM (EDKM) to address this problem. In EDKM no single 'correct' solution can be sought. Instead different value added processes for understanding and learning about the real world organisational problems should be considered using ubiquitous ICT solutions where possible.

The overall goal of this research was therefore to investigate the situation of KM infrastructures in IRI government offices. In this sense mapping and measuring key factors in situ at present to provide a view of the current state of $\mathrm{KM}$ and potential knowledge life cycles. This is followed by a prposed architecture for addressing a more dynamic EDKM and user centred view of implementing $\mathrm{KM}$ solutions. The main practical objectives were therefore:

1- To clarify the situation of six infrastructural components of KM:

$$
\begin{aligned}
& \text { strategy and policies } \\
& \text { information and communication } \\
& \text { technology } \\
& \text { KM budget } \\
& \text { organizational arrangements } \\
& \text { Staff development and mobility } \\
& \text { organizational culture }
\end{aligned}
$$

2- To make recommendations to improve required infrastructures and provide managers with lessons learned.

\section{FRAMEWORK OF STUDY}

Reviewing the literature indicates that despite the importance of $\mathrm{KM}$ in practice research on the practical real world implementation of KM policy, in contexts such as the IRI, remains in its infancy. Despite the long history of KM (from 1970's until now) articles published about the topic deal predominantly with the concepts of $\mathrm{KM}$ and here are many articles discussing definitions, principles and nature of the KM. There are fewer articles that report the implementation of $\mathrm{KM}$ programs in organizations. From this more limited set of literature the most important findings were:

- In most of the cases role of $\mathrm{KM}$ in facilitating organizational tasks was confirmed (Bong, 2004; Abdolkader, 2004).

- There is a direct relationship between investment on ICT and knowledge sharing in organizations (Khandelwal \& Gottschalk, 2003).

- Motivation and reward systems are crucial for knowledge sharing [9 \& 10].

- Organizational culture and Human centric approaches are important factors in success of KM programs (OECD, 2003; Khandelwal \& Gottschalk, 2003; Pauleen \& Mason, 2002; Ros, 2003).

- Gradually, KM finds a route into organizational strategies and become an important part of their long term objectives (OECD, 2003; United Nations, 2000; Kwan, 2003).

- Internet, intranet and staff capabilities databases play a crucial role in the success of KM programs (OECD, 2003; Abdolkader, 2004; United Nations, 2000; Kwan, 2003; KPMG, 2003; Croso et al, 2003).

- KM strategy and strategic planning for KM is one of the main critical success factors for any KM initiative (Akhgar 2009) 
- In order for a KM project to become successful there must be a clear ROI strategy in place (Akhgar 2010)

- Ubiquitous KM architecture and technological realization is the main critical success factor for any KM initiative (Akhgar and Hazzanzadeh 2011)

If emphasis it to be placed on the importance of KM and its crucial role in fulfilment of organizational missions then it seems to be rational and costeffective to invest in the vital infrastructures needed to share knowledge throughout the whole organization. Figure 2 depicts necessary infrastructures ok KM in two levels.

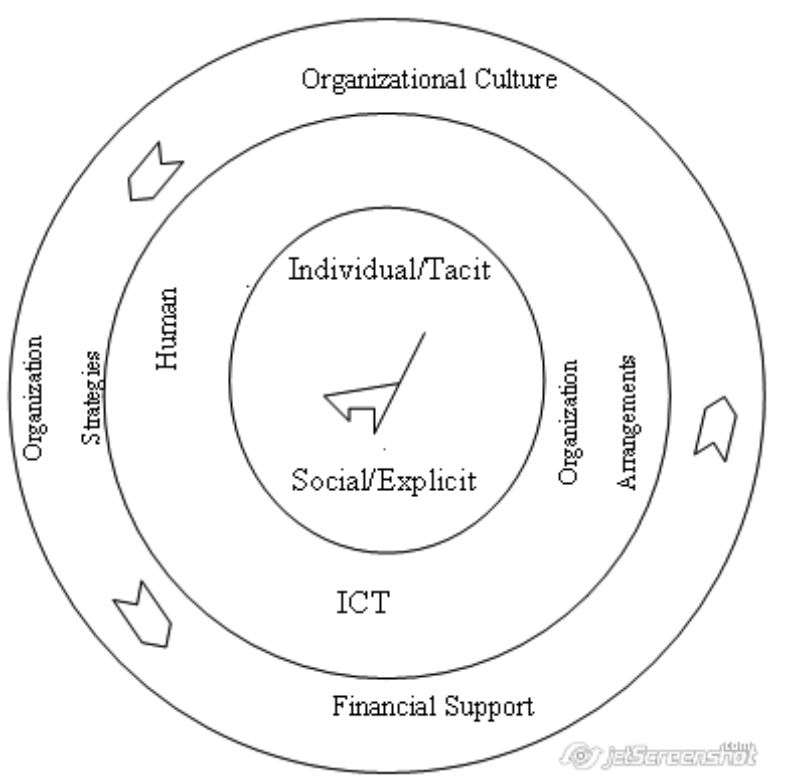

Figure 2 Knowledge Management Infrastructures for organizations

As shown in Figure 2 knowledge transformation from individual to social and from tacit to explicit shapes a core functionality of knowledge management in any organization. This process shown in Figure 2 has been named by Nonaka and Takeochi the organisational "knowledge creation process" (Nonaka \& Takeuchi, 1995). But for knowledge creation processes some key infrastructural elements are needed to underpin it. For example human resources as the mental power of organizations, organizational arrangements such as structural frameworks and ICT act as primary facilitators of $\mathrm{KM}$ in an organization. Strategic approaches to $\mathrm{KM}$ in policy documents, an organizational culture of knowledge sharing, senior management buy in and financial support of $\mathrm{KM}$ initiatives assure the success of human agency and structural arrangements. From this we can draw a research hypothesis that:

There is direct correlation between level of supportive organizational culture and extent

Table1. Ministries that were studied through research processes

\begin{tabular}{|c|c|c|c|}
\hline $\begin{array}{l}\text { Ministry of Industries } \\
\text { and Mines }\end{array}$ & $\begin{array}{l}\text { Ministry of } \\
\text { Communication and IT }\end{array}$ & Ministry of Justice & Ministry of Interior \\
\hline Ministry of Health & $\begin{array}{l}\text { Ministry of Science, } \\
\text { research and Tech. }\end{array}$ & $\begin{array}{l}\text { 16/panagement \& Planning } \\
\text { Organization }\end{array}$ & Ministry of Education \\
\hline Ministry of Petroleum & Ministry of Cooperation & Ministry of Agriculture & Ministry of Energy \\
\hline
\end{tabular}

which KM infrastructures have been provided in organizations.

In the case of our own study we would expect to see a statistical correlation between our measures of organisational culture and practice (factors 4 to 6) and our measures of organisational KM infrastructure (factors 1 to 3 ). The direction of the effect of this correlation will be explored in the action research element of the study.

\section{METHODOLOGY}

This study investigated twenty Ministries to map the $\mathrm{KM}$ infrastructure in the Iranian government. (see Table 1).

Two kinds of data about six infrastructural components were collected. First data was collected on components 1-3 which belong to whole of the organization. Gathering data required only one questionnaire to be completed for the whole organization. This questionnaire contained questions about:

1. Strategy and policies such as having KM strategy and distributing it among staffs and etc.

2. Information and communication technology including using Ubiquitous IT capabilities to share knowledge through the organization, having website and using it to share inter organizational knowledge and so on.

3. KM budget

This questionnaire was completed by the planning, budget and ICT offices in each organization.

The second set of data (components 4-6) covered those factors which could differ from one sector to another in an organization (e g. organizational culture). The second part of the questionnaire was completed by all offices, and contained questions about:

- Organizational arrangements such as having chief knowledge officer (CKO), motivations, and arrangements to acquire such roles etc.. Organization and distribution of organizational knowledge etc.

- Staff development and mobility, programmes to exchange staff with other organizations, staff training and so forth.

- Organizational culture such as the practice or intention to share and use knowledge among staff members from the viewpoint of managers. 
Two kinds of data about six infrastructural components were collected. First data was collected on components 1-3 which belong to whole of the organization. Gathering data required only one questionnaire to be completed for the whole organization. This questionnaire contained questions about:

1. Strategy and policies such as having KM strategy and distributing it among staffs and etc.

2. Information and communication technology including using Ubiquitous IT capabilities to share knowledge through the organization, having website and using it to share inter organizational knowledge and so on.

3. KM budget

This questionnaire was completed by the planning, budget and ICT offices in each organization.

The second set of data (components 4-6) covered those factors which could differ from one sector to another in an organization (e g. organizational culture). The second part of the questionnaire was completed by all offices, and contained questions about:

- Organizational arrangements such as having chief knowledge officer (CKO), motivations, and arrangements to acquire such roles etc.. Organization and distribution of organizational knowledge etc.

- Staff development and mobility, programmes to exchange staff with other organizations, staff training and so forth.

- Organizational culture such as the practice or intention to share and use knowledge among staff members from the viewpoint of managers.

Overall, 20 questionnaires were collected for the first three components and 294 questionnaires were collected from individual departments with regard to the second three components. Completed questionnaires were controlled for possible errors through cross referencing with additional contacts and organisational websites. For the proposed architecture discussed later in the paper we have used a number of short cycle action research projects from the widest possible set of client organizations. The "lesson learned" from each action research cycle were recorded. The latter was then categorized into elements of a KM cycle as laid out in Figure 1 in order to create a generalized view of the findings. The overall methodological approach is illustrated in the figure 3 below:indent.

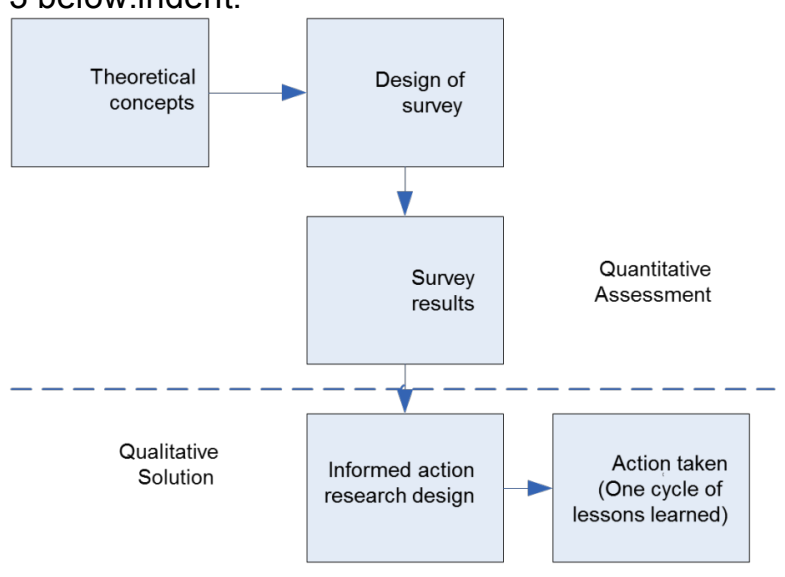

Figure 3: The overall methodological approach

\section{RESEARCH FINDINGS}

The presence of $\mathrm{KM}$ in policy documents of an organization is an inevitable first step to be taken. After policy making the second step will be financial support for $\mathrm{KM}$ initiatives including human resources, technical infrastructures and organizational arrangements which enable an organization to fulfill its mission. The maximum possible score in components 1-3 (Policies, ICT and Budgets) was 86 . The Ministry of Industry, as the highest scoring organization, captured only 44.93 , which is just over $50 \%$ of the maximum total score. This is not a good indicator of effective KM initiatives in the studied organizations. 
Table2. The score of organizations in first three components (Policies, ICT and Budgets)

\begin{tabular}{|c|l|c|c|c|c|}
\hline \multicolumn{5}{|c|}{ Maximum Possible Score $=86$} \\
\hline Rank & \multicolumn{1}{|c|}{ Organizations } & IT & $\begin{array}{c}\text { Policies \& } \\
\text { Strategies }\end{array}$ & Budget & $\begin{array}{c}\text { Total } \\
\text { Score }\end{array}$ \\
\hline 1 & Ministry of Industries and Mines & 37.95 & 0.98 & 6 & 44.93 \\
\hline 2 & Ministry of Communication and IT & 34.04 & 0.98 & 8 & 43.02 \\
\hline 3 & Ministry of Justice & 31.05 & 0.00 & 8 & 39.05 \\
\hline 4 & Ministry of Interior & 33.58 & 0.98 & 4 & 38.56 \\
\hline 5 & Ministry of Health & 31.05 & 0.00 & 6 & 37.05 \\
\hline 6 & Ministry of Science, research and Tech. & 29.90 & 0.98 & 6 & 36.88 \\
\hline 7 & Management \& Planning Organization & 29.9 & 0.00 & 6 & 35.9 \\
\hline 8 & Ministry of Education & 29.9 & 0.00 & 6 & 35.9 \\
\hline 9 & Ministry of Petroleum & 31.05 & 0.00 & 4 & 35.05 \\
\hline 10 & Ministry of Cooperation & 28.06 & 0.98 & 6 & 35.04 \\
\hline 11 & Ministry of Agriculture & 28.06 & 0.00 & 6 & 34.06 \\
\hline 12 & Ministry of Energy & 28.98 & 0.00 & 5 & 33.98 \\
\hline 13 & Ministry of Transportation & 25.99 & 0.00 & 3 & 28.99 \\
\hline 14 & Ministry of Housing and Urban & 23 & 0.00 & 4 & 27 \\
\hline 15 & Ministry of Welfare & 19.55 & 0.00 & 5 & 24.55 \\
\hline 16 & Ministry of Foreign Affaires & 16.56 & 0.98 & 4 & 21.54 \\
\hline 17 & Ministry of Economic Affaires & 16.10 & 0.00 & 5 & 21.10 \\
\hline 18 & Ministry of Culture & 14.95 & 0.00 & 4 & 20.95 \\
\hline 19 & Ministry of Labor and Social Affaires & 14.95 & 0.00 & 5 & 19.95 \\
\hline 20 & Ministry of Commerce & 17.94 & 0.98 & 7 & 18.92 \\
\hline & Mean & 26.13 & 0.34 & 5.4 & 31.78 \\
\hline
\end{tabular}

With regard to the second set of criteria measured across departments within each ministry Table 3 indicates that 6 out of 20 organizations gained a score greater than $50 \%$ of the maximum score (128) and mean score was close to this at 60.84 . The highest score belongs to the Ministry of Cooperation and lowest score is of the Ministry of Housing. The scores of 10 organizations were greater than the mean. In this standard deviation and the range between highest and lowest score is higher than that for in the results for the first three factors. In the case of our second set of factors we have enough within group cases (294 in total) to compare scores with relevant parametric tests for each of the component factors and overall score.

Table 4 shows the results of an ANOVA of the Organizational Arrangements scores. This provides a test of the statistical significance of the variation in means between each Ministry. Results presented in Table 4 show that there is significant difference between organizations about organizational arrangements toward managing organizational knowledge. Table 5 presents a Duncan's new multiple range post-hoc test to examine significance of differences and the statistical grouping of similar categories - in this case Ministries. Duncan's new multiple range test (MRT) is a multiple comparison procedure developed by David B. Duncan which provides detail of the 'clustering' of 'treatments' within the ANOVA. In this case the analysis indicates which sets of Ministries had similar (mean) results. Results presented in table 4 shows that there is significant difference between organizations about organizational arrangements toward managing organizational knowledge. The pattern of differences between organizations and the grouping of similar organizations (by score) derives from the Duncan's Test (Table 5).
Table3. The score of organizations in second three components (Organizational Arrangements, Organizational Culture \& Staff Development)

\begin{tabular}{|c|c|c|c|c|c|}
\hline \multicolumn{6}{|c|}{ Maximum Possible Score $=128$} \\
\hline Rank & Organizations & $\begin{array}{l}\text { Organizational } \\
\text { Arrangements }\end{array}$ & $\begin{array}{l}\text { Organizational } \\
\text { Culture }\end{array}$ & $\begin{array}{c}\text { Staff } \\
\text { Development \& } \\
\text { Mobility }\end{array}$ & $\begin{array}{l}\text { Total } \\
\text { Score }\end{array}$ \\
\hline 1 & Ministry of Cooperative & 32 & 9.08 & 25.53 & 92.11 \\
\hline 2 & $\begin{array}{l}\text { Ministry of Science, Research and } \\
\text { Tech }\end{array}$ & 36.93 & 9.6 & 35.07 & 81.6 \\
\hline 3 & $\begin{array}{l}\text { Management \& Planning } \\
\text { Organization }\end{array}$ & 40.07 & 12 & 24.07 & 76.14 \\
\hline 4 & Ministry of Energy & 36.33 & 9.2 & 25.6 & 71.13 \\
\hline 5 & Ministry of Communications \& IT & 36.07 & 9.34 & 24.4 & 69.81 \\
\hline 6 & Ministry of Petroleum & & 9.32 & 25.93 & 65.25 \\
\hline 7 & Ministry of Interior & 31.64 & 8.8 & 23.33 & 63.77 \\
\hline 8 & Ministry of Education & 34.73 & 9.47 & 18.27 & 62.48 \\
\hline 9 & Ministry of Commerce & 26 & 9.47 & 26.87 & 62.34 \\
\hline 10 & Ministry of Economic Affaires & 36.13 & 9.33 & 15.73 & 61.19 \\
\hline 11 & Ministry of Agriculture & 32.33 & 8.73 & 16.93 & 57.99 \\
\hline 12 & Ministry Industries and Mines & 31.2 & 9.28 & 17.07 & 57.55 \\
\hline 13 & Ministry of Health & 28.67 & 9.47 & 18.53 & 54 \\
\hline 14 & Ministry of Justice & 27.33 & 10 & 16 & 53.33 \\
\hline & Ministry of Foreign Affaires & 28.46 & 8.27 & 16.27 & \\
\hline 16 & Miristry of Transportation & 25.4 & 10.4 & 15.2 & 51 \\
\hline 17 & Ministry of Labor \& Social Affaires & 25.2 & 10.67 & 13.4 & 49.27 \\
\hline 18 & Ministry of Culture & 25.93 & 9.2 & 11.6 & 46.73 \\
\hline 19 & Ministry of Welfare & 20.2 & 8.4 & 17.33 & 45.93 \\
\hline 20 & Ministry of Housing & 16.87 & 9.07 & 17.2 & 43.14 \\
\hline & Mean & 30.07 & 9.28 & 20.22 & 60.84 \\
\hline
\end{tabular}

Table 4. ANOVA results for the component "Organizational Arrangements"

\begin{tabular}{|l|c|c|c|c|c|}
\hline & $\begin{array}{c}\text { Sum of } \\
\text { squares }\end{array}$ & df & $\begin{array}{c}\text { Mean } \\
\text { Squares }\end{array}$ & F & Sig. \\
\hline $\begin{array}{l}\text { Between } \\
\text { groups }\end{array}$ & 11285.75 & 19 & 592.56 & 76.12 & 0.0 \\
\hline $\begin{array}{l}\text { within } \\
\text { groups }\end{array}$ & 2226.40 & 289 & 7.78 & & \\
\hline Total & 13485.15 & 293 & & & \\
\hline
\end{tabular}

Table5. Duncan Test results for "organizational arrangements

\begin{tabular}{|c|c|c|c|c|c|c|c|c|c|c|c|}
\hline \multirow{2}{*}{ Organizations } & \multirow[t]{2}{*}{$\mathrm{N}$} & \multicolumn{10}{|c|}{ Subset for alpha $=.05$} \\
\hline & & 1 & 2 & 3 & 4 & 5 & 6 & 7 & 8 & 9 & 10 \\
\hline Ministry of Housing & 15 & 16.87 & & & & & & & & & \\
\hline Ministry of Welfare & 15 & & 20.20 & & & & & & & & \\
\hline Ministry of Labor \& Social Affaire & 15 & & & 25.20 & & & & & & & \\
\hline Ministry of Transpootation & 15 & & & 25.40 & & & & & & & \\
\hline Ministry of Culture & 15 & & & 25.93 & & & & & & & \\
\hline Ministry of Commerce & 15 & & & 26.00 & & & & & & & \\
\hline Ministry of Justice & 9 & & & 27.33 & 27.33 & & & & & & \\
\hline Ministry of Foreign Affaires & 15 & & & & 28.47 & 28.47 & & & & & \\
\hline Ministry of Health & 15 & & & & 28.67 & 28.67 & & & & & \\
\hline Ministry of Petroleum & 15 & & & & & 30.00 & 30.00 & & & & \\
\hline Ministry of Industries \& Mines & 15 & & & & & & 31.20 & 31.20 & & & \\
\hline Ministry of Interior & 15 & & & & & & 31.64 & 31.64 & & & \\
\hline Ministry of Cooperative & 15 & & & & & & 32.00 & 32.00 & & & \\
\hline Ministry of Agriculture & 15 & & & & & & & 32.33 & & & \\
\hline Ministry of Education & 15 & & & & & & & & 34.73 & & \\
\hline Ministry of Communication \& IT & 15 & & & & & & & & 36.07 & 36.07 & \\
\hline Ministry of Economic Affaires & 15 & & & & & & & & 36.13 & 36.13 & \\
\hline Ministry of Science, Research \&. & 15 & & & & & & & & 36.93 & 36.93 & \\
\hline Ministry of Energy & 15 & & & & & & & & & 37.08 & \\
\hline Management \& Planning Org. & 15 & & & & & & & & & $\sqrt{60}$ & 40.07 \\
\hline Sig. & & 1.00 & 1.00 & 0.06 & 0.22 & 0.16 & 0.08 & 0.32 & 0.05 & 0.38 & 7,00 \\
\hline
\end{tabular}

In Table 5, all organizations are sorted in ascending order by their scores, and then grouped according to their homogeneity. The ministry of housing gained highest and Management and Planning Organization (MPO) the lowest. Organizations listed in the same column do not have statistically significant differences with each other. For example the fact MPO is in a separate column means it is statistically significantly different from all the other organizations. 
Table6. ANOVA test results for the component "Staff development"

\begin{tabular}{|l|l|l|l|c|c|}
\hline & $\begin{array}{c}\text { Sum of } \\
\text { Squares }\end{array}$ & \multicolumn{1}{c|}{ df } & $\begin{array}{c}\text { Mean } \\
\text { Squares }\end{array}$ & F & $\begin{array}{c}\text { Sig } \\
\text {. }\end{array}$ \\
\hline $\begin{array}{l}\text { Between } \\
\text { Groups }\end{array}$ & 9705.718 & 19 & 510.827 & 116.29 & 0.0 \\
\hline $\begin{array}{l}\text { within } \\
\text { Groups }\end{array}$ & 12.69 .467 & 289 & 4.393 & & \\
\hline Total & 10975.184 & 293 & & & \\
\hline
\end{tabular}

Table7. Duncan's test results for the component "Staff development and mobility"

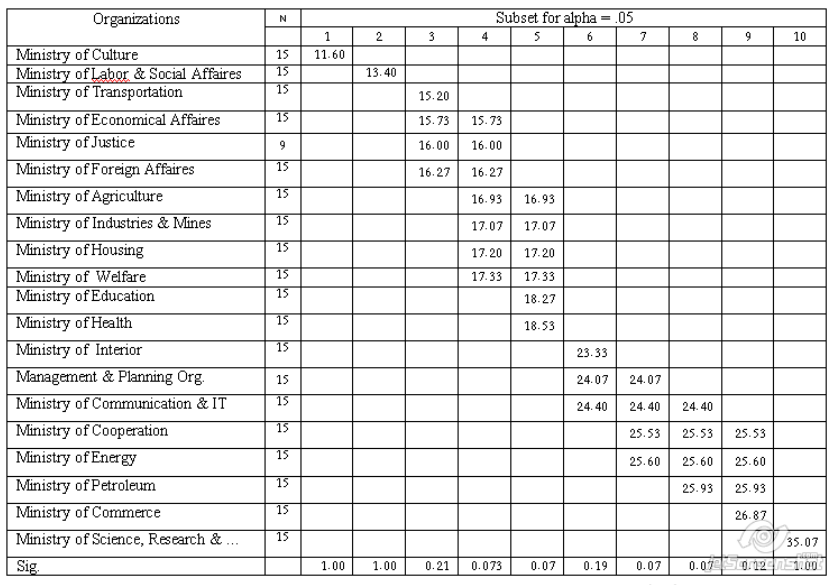

As represented in Table 7, the Ministry of Science, Research and Technology which deals with higher education gained highest score and the Ministry of Culture gained the lowest score. Furthermore, we can see groupings of organizations in the columns of table.

Table8. Results of ANOVA test for the component of "Organizational culture"

\begin{tabular}{|l|l|l|l|l|l|}
\hline & $\begin{array}{c}\text { Sum of } \\
\text { Squares }\end{array}$ & Df & $\begin{array}{c}\text { Mean } \\
\text { Squares }\end{array}$ & F & Sig. \\
\hline $\begin{array}{l}\text { Between } \\
\text { Groups }\end{array}$ & 114.769 & 19 & 6.040 & 2.589 & 0.00 \\
\hline $\begin{array}{l}\text { within } \\
\text { Groups }\end{array}$ & 674.267 & 289 & 2.333 & & \\
\hline \multicolumn{1}{|c|}{ Total } & 789.036 & 293 & & & \\
\hline
\end{tabular}

Table 8 shows the results of ANOVA test of the scores for the third component "organizational culture". Once again there is statistically significant difference between organizations on this measure. Table 9 shows the Duncan's test results in respect of this measure.
Table 9. Duncan's test results for the component "Organizational culture"

\begin{tabular}{|c|c|c|c|c|c|c|}
\hline Organizations & $\mathrm{N}$ & \multicolumn{5}{|c|}{ Subset for alpha $=.05$} \\
\hline Ministry of Foreign Affaires & 15 & 8.27 & & & & \\
\hline Ministry of Welfare & 15 & 8.40 & & & & \\
\hline Ministry of Agriculture & 15 & 8.73 & 8.73 & & & \\
\hline Ministry of Interior & 15 & 8.80 & 8.80 & & & \\
\hline Ministry of Cooperation & 15 & 9.08 & 9.07 & 9.07 & & \\
\hline Ministry of Housing & 15 & 9.07 & 9.07 & 9.07 & & \\
\hline Ministry of Culture & 15 & 9.20 & 9.20 & 9.20 & & \\
\hline Ministry of Energy & 15 & 9.20 & 9.20 & 9.20 & & \\
\hline Ministry of Economic Affaires & 15 & 9.33 & 9.33 & 9.33 & & \\
\hline Ministry of Industries \& Mines & 15 & 9.28 & 9.28 & 9.28 & & \\
\hline Ministry of Petroleum & 15 & 9.32 & 9.32 & 9.32 & & \\
\hline Ministry of Communication \& IT & 15 & 9.34 & 9.34 & 9.34 & & \\
\hline Ministry of Education & 15 & 9.47 & 9.47 & 9.47 & 9.47 & \\
\hline Ministry of Commerce & 15 & 9.47 & 9.47 & 9.47 & 9.47 & \\
\hline Ministry of Health & 15 & 9.47 & 9.47 & 9.47 & 9.47 & \\
\hline Ministry of Science, Research \& Technology & 15 & 9.60 & 9.60 & 9.60 & 9.60 & \\
\hline Ministry of Justice & 9 & & 10 & 10 & 10 & \\
\hline Ministry of Transpootation & 15 & & & 10.4 & 10.4 & \\
\hline Ministry of Labor \& Social Affaires & 15 & & & & 10.67 & \\
\hline Management \& Planning Organization & 15 & & & & & 12 \\
\hline Sig. & & 0.055 & 0.067 & 0.051 & 0 & C1:800 \\
\hline
\end{tabular}

According to Table 9, The Management and Planning organization captured highest score and the Ministry of Foreign Affairs gained lowest score. The key result from this analysis is the lower levels of variation between the Ministries. We can conclude that in comparison with other components, the situation of organizational culture seems appears similar and this may indicate wider organisational factors within government.

If we now turn to our hypothesis that there will be a correlation between our two sets of factors Table 10 shows the results of Pearson's correlation of these two sets of scores.

Table10. Pearson's correlation result

\begin{tabular}{|l|l|l|}
\hline \multicolumn{2}{|c|}{ Pearson Correlation } & KMI Level \\
\hline \multirow{2}{*}{$\begin{array}{l}\text { Organizational } \\
\text { Culture }\end{array}$} & YCorrelation co efficiency & 0.78 \\
\cline { 2 - 3 } & Sig. (2-tailed) & 0.023 \\
\cline { 2 - 3 } & $\mathrm{N}$ & 20 \\
\hline
\end{tabular}

Table 10 indicates a statistical correlation between supportive organizational culture and KM infrastructures. This fits with the literature discussed earlier which identifies organizational culture and practice as having a crucial role in success of KM programs [6, 9, 10 \& 11]. It also provides a very basic deductive test of the questionnaires as a tool for the general assessment of $\mathrm{KM}$ implementation in organisations. Though further work with organisations outside of IRI would need to be conducted to further refine and validate the tool. Having said this we need to reflect on the real world context of KM in the Ministries to understand potential interventions and the level of organsitional challenge in meeting policy goals for KM. To compare the situation of of the studied organizations with an hypothetical desired maximum level KM infrastructure and supporting organisational culture and practice we calculated the difference between organizations scores with the potential maximum score. The 
maximum possible score was 214 . Table 11 shows the results of this comparison.

Table11. Total score of organizations in compare with Maximum possible score

\begin{tabular}{|l|l|c|c|}
\hline \multicolumn{3}{|c|}{ Maximum Possible Score $=214$} \\
\hline Rank & \multicolumn{1}{|c|}{ Organizations } & Total Score & $\begin{array}{c}\text { Differences with } \\
\text { Maximum possible } \\
\text { Score }\end{array}$ \\
\hline 1 & Ministry of Science, research \& Tech. & 118.48 & 95.52 \\
\hline 2 & Ministry of Communication and IT & 112.83 & 101.17 \\
\hline 3 & Management \& Planning Organization & 112.04 & 101.96 \\
\hline 4 & Ministry of Energy & 105.11 & 108.89 \\
\hline 5 & Ministry of Industries and Mines & 102.48 & 11.52 \\
\hline 6 & Ministry of Interior & 102.33 & 11.67 \\
\hline 7 & Ministry of Cooperative & 101.65 & 112.35 \\
\hline 8 & Ministry of Petroleum & 100.3 & 113.7 \\
\hline 9 & Ministry of Education & 98.37 & 115.63 \\
\hline 10 & Ministry of Health & 93.72 & 120.28 \\
\hline 11 & Ministry of Justice & 92.38 & 121.62 \\
\hline 12 & Ministry of Agriculture & 92.05 & 121.95 \\
\hline 13 & Ministry of Commerce & 88.26 & 125.74 \\
\hline 14 & Ministry of Economic Affaires & 82.29 & 131.71 \\
\hline 15 & Miristry of Transportation & 79.99 & 134.01 \\
\hline 16 & Ministry of Foreign Affaires & 74.54 & 139.46 \\
\hline 17 & Ministry of Welfare & 70.48 & 143.52 \\
\hline 18 & Ministry of Housing & 70.14 & 143.86 \\
\hline 19 & Ministry of labor \& Social Affaires & 69.22 & 144.78 \\
\hline 20 & Ministry of Culture & 65.68 & 148.32 \\
\hline & Mean & 91.62 & 912.38 \\
\hline
\end{tabular}

As shown in Table 11 the score of all organizations are below the potential maximum score. The highest score belongs to the Ministry of Science, Research and Technology and this far from the maximum score. Again there is considerable variation between ministries with 12 out of 20 organizations gaining scores greater than the mean (91.62). The mean difference from the maximum score is 112.38 (almost $50 \%$ of the maximum score). Though this result appears to indicate a gap between policy goals for $\mathrm{KM}$ and actual practice the key issue is that of supporting the move towards greater use of $\mathrm{KM}$. These results are also only a snapshot of the level of KM at the point of survey. As noted above within these scores there is variation in each factor which indicates variation in the $\mathrm{KM}$ context and challenges facing each Ministry?

If we take this data as an indication of the need for further work to meet KM policy goals then a number of issues and actions follow. In order to propose the required level of change, we have suggested the following generic architecture as a roadmap for governmental organizations. For that, we have critically included a number of $\mathrm{KM}$ strategic initiatives in our investigation. Intentionally we have chosen a wide range of industries and project sizes in order to extract a common set of factors contributing to successful deployment of a KMS. The industries (with direct governmental responsibilities) chosen were as follows:

1. Oil, Gas and Petrochemical,

2. Automotive, Finance

3. Security (including law enforcement agencies)
The proposed architecture has 3 interrelated perspectives:

- Strategic Propositions (Business /National Programs View)

- KM Tactical models (Core KM View)

- IT Perspectives (IT View)

The foundation of the model is based in organisational strategy. As noted earlier it is observed that a KMS becomes successful only if the following strategic considerations are first met:

1. KM Strategic proposition (Why, What, How, When)

2. Development of the KMS CSFs including the project key performance indicators.

3. Identification of the impact of $\mathrm{KM}$ on business processes such as human resources, governmental extended value chains, enterprise data models and product/services offerings

At the core our model are the KM life cycle elements. It addresses all the necessary components needed for tactical realisation of a KM project (Akhgar and Mosakhani 2010) from knowledge definition and models to formation of COPs.

The outer layer of our model (IT perspective) addresses the notion of knowledge gateways where the elements of KM life cycle can be visualisde and communicated throughout the enterprise' extended value system. This may be via one or more key infrastructures such as the Internet, an Intranet, Extranet or Cloud Computing platform. This will be based on the criteria identified and justified at the business perspective layer.

Therefore in order the have a clear KMS, enterprises need to address and understand the following as the minimum requirements for any future KM initiative:

- KM Strategic Proposition (including why $\mathrm{KM}$, value systems for $\mathrm{KM}$, strategic impact of $\mathrm{KM}, \mathrm{KPIs}$ )

- KM Project Aim and Objectives (including CSFs, KPls, key decisions related to KM, project resources, project management methodology)

- Infrastructure (including current IS and IT)

- Organisational Structure, Culture and Human resources (including corporate value system, reward systems, new organisational roles and responsibilities, staff training etc.) 
- Business Processes (including process models and process owners)

- Enterprise Value Systems (including clear assessment of enterprise value chain and the extended value chain, knowledge assessment, current data models and any service descriptions - both logical and physical services)

- Products and Services offering (including possible impact of $\mathrm{KM}$ on product and services)

- Core of KM (including COP, organisational knowledge definition, enterprises taxonomy, knowledge creation, storage and visualisation, collaboration mechanisms and constant assessment of KM usefulness and added value)

- IT and Technology issues (including how, what and business justification and implementation plan)

Further work intends to develop the above architecture based on W3C business model. This will allow organizations to adopt and adapt it based on their own corporate needs. It is hoped further work will allow the development and maintenance of a wiki to support the enhancement of and future development of this architecture.

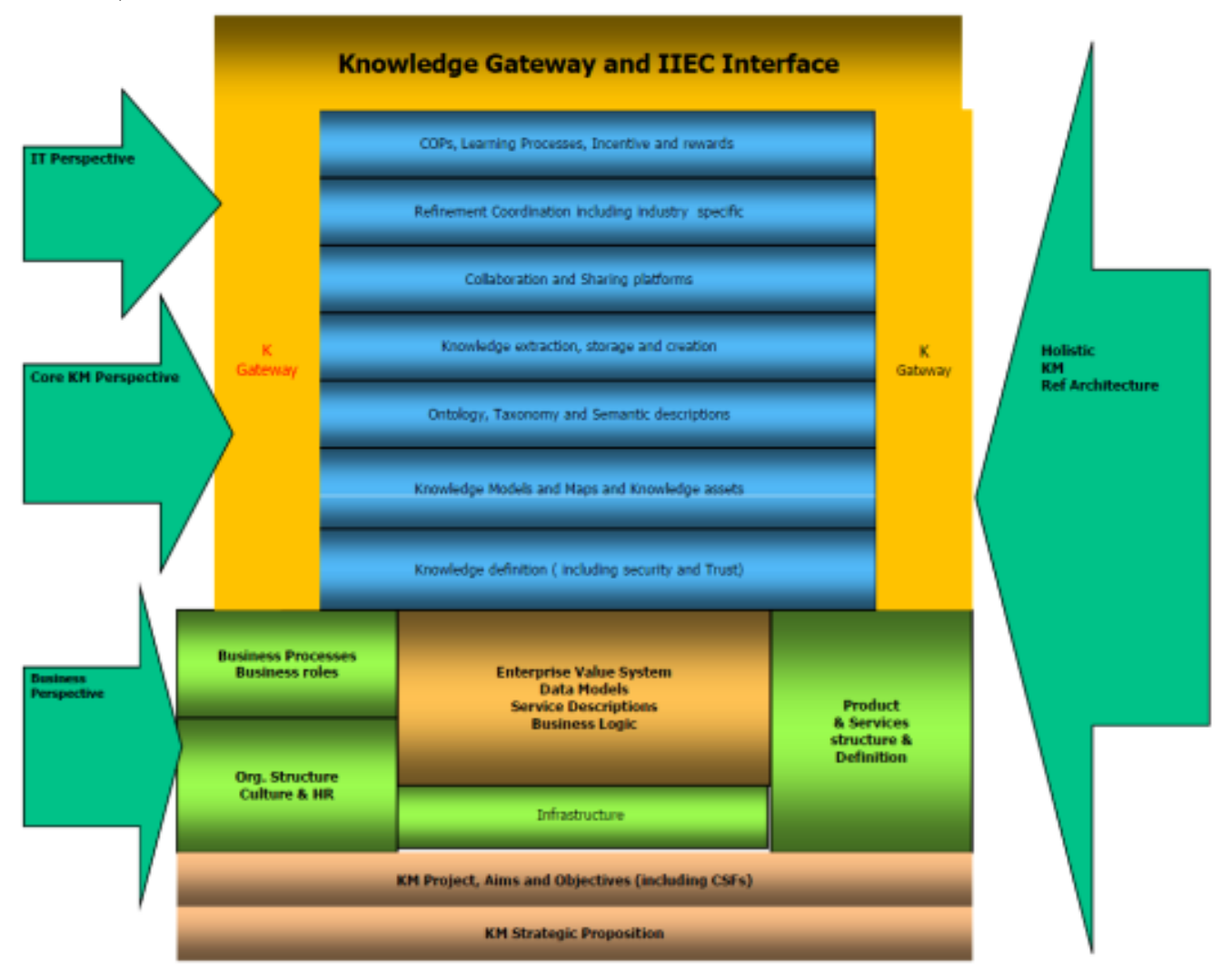

Figure 4 Proposed Reference Architecture

\section{CONCLUSIONS}

It seems that the knowledge society presents different challenges to orgasnaitons. Information and Communication Technologies (ICT) developments have brought about the realization of a knowledge society where knowledge becomes as a core material for decision making in all aspects of social life. In entering this information and communication era governments have sought to develop and enhance their national and social in knowledge base accordingly. In the practical context of the running and management of government agencies KM needs to be an important part of this process. This article represented a summarized report of a study that sought to investigate the situation of $\mathrm{KM}$ infrastructures in the government of IRI. Some lessons from the results are:

- The importance of knowledge in moving toward sustainable development is understood by the government [5].

- The data would indicate that the government has yet to manage organizational knowledge to maximum effect. Coordinated national plans for key organizations could improve the situation informed by an assessment of the specific strengths and weaknesses in each organisation.

- There is serious need to set a comprehensive standard for $\mathrm{KM}$ 
infrastructures in key government organizations.

- Since extra organizational relations are the important part of KM, organizations need to provide cooperate with each other.

- Supportive organisational culture is crucial to the success of organizations moves toward effective knowledge management. Organizations need to improve the engagement of staff members in knowledge exchange.

- Reward systems need to encourage people to cooperate with knowledge management initiatives; this accordingly will improve the supportive organizational culture.

ICTs are an accelerator of organizational change and facilitator of knowledge sharing; proper investment on ICT will provide organizations with capacity to fulfill KM initiatives effectively. Traditional rigid top-down and hierarchical structure of organizations may not have the best capacity for knowledge flow and often work as a main barrier.

Since, policy documents drive and mobilize organizational capabilities towards predefined goals and objectives, presence of KM in top policy documents of organizations will provide legal facilities to and financial allocations for related initiatives. Longitudinal plans for $\mathrm{KM}$ will help organizations to provide bedrocks for consequent action.

In brief, knowledge management is not a mere technical issue and mere technical arrangements will not assure its success. Implementing effective knowledge sharing mechanisms which all people in any organizational engage with is the key start point of any $\mathrm{KM}$ initiative and this still remains a human not technical issue.

\section{REFERENCES}

OECD. (1996). the knowledge- based economy. Paris: OECD. April Report. PP. 24-26.

World Bank. (1998). World development report: Knowledge for development. Oxford press.

World Bank. (2002). The knowledge assessment methodology and scorecards. [Online]. Available at: http://worldbank.org/gdln/programs/kam2002/meth odology.htm

IRI 4th development plan law (2005- 2009). Tehran: Management and Planning organization, P. 69 ( Persian).

OECD. (2003). Conclusions from the results of the survey of knowledge management practices for ministries/ departments/ agencies of central government in OECD member countries. OECD; Human Resources Management Working Party. Paris. February. No. JT00138295.

Bong, Sun-Hark. (2004). Effective team processes for technology internationalization with special emphasis on knowledge management: Successful late starter, Samsung case. International journal of technology management. Vol. 27, No. 1, pp. 16.

Abdolkader, A. H. (2004). Readiness of IDSC to adopt knowledge management. In: Knowledge management: Current issues and challenges. Coakes, E. (Ed.). London: IRM Press.

Khandelwal, V. \& Gottschalk, P. (2003). A knowledge management survey of Australian law firms. School of Computing and Information Technology. University of western Sydney. Technical report No. CIT/5/2003.

Pauleen, D. \& Mason, D.(2002). New Zealand knowledge management survey: Barriers and drivers of KM uptake. School of Information Management. Victoria University of Wellington.

Ros, J. (2003). Measuring the benefits of knowledge management at the financial services Authority: A case study. Journal of Information Science. Vol. 29, No. 6. PP. 475-88.

United Nations. (2000). Knowledge management and Information technology. Consultative committee on program and operations. Acc/2000/POQ/CRP. 14, 14 September.

Kwan, M. M. (2003). Process oriented knowledge management: a case study. Journal of the operational research society. Vol. 54, No. 2. P. 204. KPMG. (2003). Insights from KPMG's European knowledge management survey. KPMG advisory services.

Croso, Mariano; Martini, Antonella; pellegrini, Luisa \& Paolucci, Emilio. (2003). Technological and organizational tools for knowledge management: In search of Configuration. Small Business Economics. Vol. 21, No. 4. P.397.

Nonaka, I \& Takeuchi, H. (1995). The knowledgecreating company : how Japanese companies create the dynamics of innovation, Oxford University Press, New York.

Akhgar, B, Hassanzadeh, M and Yates, S (2011); Architectural Roadmap for KM deployment, IKE 2011. US WorldComp 2011 